Supplement of Biogeosciences, 13, 6171-6182, 2016

http://www.biogeosciences.net/13/6171/2016/

doi:10.5194/bg-13-6171-2016-supplement

(C) Author(s) 2016. CC Attribution 3.0 License.

(c) (i)

Supplement of

\title{
Ocean acidification challenges copepod phenotypic plasticity
}

Anu Vehmaa et al.

Correspondence to: Anu Vehmaa (asvehmaa@gmail.com)

The copyright of individual parts of the supplement might differ from the CC-BY 3.0 licence. 
Table S1. pH values measured before and after the incubations. After incubation $\mathrm{pH}$ values for the Baltic are averaged from six measurements.

\begin{tabular}{lcccccccccc}
\hline & \multicolumn{7}{c}{ pH before - after incubation } \\
\cline { 2 - 9 } & \multicolumn{2}{c}{ Day 3 } & \multicolumn{2}{c}{ Day 10 } & \multicolumn{2}{c}{ Day 17 } & \multicolumn{2}{c}{ Day 24 } & Day 45 \\
& EPR, PL & EH, DI & EPR, PL & EH, DI & EPR, PL & EH, DI & EPR, PL & EH, DI & EPR, PL \\
\hline MC 1 & $8.12-8.13$ & $7.97-7.51$ & $8.14-8.18$ & $8.2-7.95$ & $8.08-8.11$ & $8.10-7.96$ & $7.98-8.07$ & $8.05-7.92$ & $7.82-7.82$ \\
MC 3 & $7.50-7.63$ & $7.62-7.61$ & $7.62-7.66$ & $7.67-7.81$ & $7.61-7.64$ & $7.64-7.68$ & $7.59-7.69$ & $7.69-7.72$ & $7.69-7.69$ \\
MC 5 & $8.18-8.07$ & $8.08-7.79$ & $8.10-8.17$ & $8.16-8.00$ & $8.07-8.08$ & $8.10-7.83$ & $7.90-8.00$ & $8.01-7.84$ & $7.85-7.89$ \\
MC 6 & $7.66-7.71$ & $7.66-7.67$ & $7.63-7.73$ & $7.73-7.87$ & $7.72-7.78$ & $7.73-7.69$ & $7.63-7.77$ & $7.76-7.72$ & $7.75-7.73$ \\
MC 7 & $7.97-7.85$ & $7.82-7.69$ & $7.90-7.97$ & $7.95-7.90$ & $7.91-7.94$ & $7.89-7.74$ & $7.84-7.88$ & $7.90-7.82$ & $7.82-7.84$ \\
MC 8 & $7.45-7.59$ & $7.50-7.58$ & $7.53-7.61$ & $7.57-7.74$ & $7.58-7.58$ & $7.59-7.60$ & $7.50-7.65$ & $7.64-7.68$ & $7.62-7.68$ \\
Baltic & 8.15 & $7.92-7.68$ & 8.24 & $7.9-7.95$ & 8.36 & $7.90-7.90$ & 8.08 & $7.88-7.84$ & 7.67 \\
\hline
\end{tabular}


Table S2. Number of nauplii hatched / total number of eggs incubated, as well as nauplii development index (DI) in the egg transplant experiment.

\begin{tabular}{|c|c|c|c|c|c|c|c|c|c|}
\hline Mesocosm & Hatching & Day 3 & & Day 10 & & Day 17 & & Day 24 & \\
\hline & & $\begin{array}{l}\text { nauplii / } \\
\text { total eggs }\end{array}$ & DI & $\begin{array}{l}\text { nauplii / } \\
\text { total eggs }\end{array}$ & DI & $\begin{array}{l}\text { nauplii / } \\
\text { total eggs }\end{array}$ & DI & $\begin{array}{l}\text { nauplii / } \\
\text { total eggs }\end{array}$ & DI \\
\hline \multirow[t]{2}{*}{ MC 1} & MC & $43 / 47$ & 1.02 & $85 / 86$ & 0.99 & $35 / 37$ & 1.27 & $26 / 28$ & 1.43 \\
\hline & Baltic & $64 / 77$ & 1.01 & $53 / 54$ & 1.02 & $76 / 86$ & 1.12 & $23 / 23$ & 1.65 \\
\hline \multirow[t]{2}{*}{ MC 3} & MC & $60 / 70$ & 1.10 & $45 / 49$ & 0.94 & $59 / 62$ & 1.10 & $21 / 24$ & 1.42 \\
\hline & Baltic & $48 / 54$ & 1.19 & 77 / 81 & 0.98 & $52 / 54$ & 1.13 & $20 / 24$ & 1.33 \\
\hline \multirow[t]{2}{*}{ MC 5} & MC & $109 / 119$ & 1.47 & $60 / 62$ & 1.00 & $29 / 30$ & 1.53 & $14 / 15$ & 1.13 \\
\hline & Baltic & $22 / 25$ & 1.16 & 86 / 91 & 0.97 & $63 / 66$ & 1.26 & $30 / 33$ & 1.33 \\
\hline \multirow[t]{2}{*}{ MC 6} & MC & na & na & $52 / 52$ & 1.02 & $33 / 35$ & 1.09 & $31 / 33$ & 1.30 \\
\hline & Baltic & $55 / 56$ & 1.50 & $149 / 158$ & 0.97 & $29 / 30$ & 1.20 & $33 / 34$ & 1.79 \\
\hline \multirow[t]{2}{*}{ MC 7} & MC & $75 / 82$ & 1.33 & $66 / 68$ & 0.97 & $48 / 49$ & 1.22 & $11 / 11$ & 1.46 \\
\hline & Baltic & $52 / 59$ & 1.17 & $52 / 56$ & 0.96 & $40 / 42$ & 1.10 & $16 / 18$ & 1.50 \\
\hline \multirow[t]{2}{*}{ MC 8} & MC & $51 / 60$ & 1.03 & 49 / 51 & 0.96 & $35 / 38$ & 1.03 & $20 / 21$ & 1.24 \\
\hline & Baltic & $45 / 47$ & 1.21 & 92 / 94 & 1.00 & $33 / 37$ & 1.03 & $27 / 27$ & 1.63 \\
\hline
\end{tabular}

